\title{
Pharmacovigilance: An Overview
}

\author{
Saurabh Nimesh and Vrish Dhwaj Ashwlayan* \\ Department of Pharmaceutical Technology, Meerut Institute of Engineering and Technology, NH-58 Baghpat Crossing \\ Bypass Road, Meerut-250005 Uttar Pradesh, India.
}

Received: May 16, 2018; Accepted: May 30, 2018; Published: May 31, 2018

*Corresponding author: Vrish Dhwaj Ashwlayan, Department. of Pharmaceutical Technology, Meerut Institute of Engineering and Technology, NH-58 Baghpat Crossing Bypass Road, Meerut-250005 Uttar Pradesh, India, Tel: 91-9412493228; E-mail: vrish.ashwlayan@miet.ac.in

\section{Abstract}

Pharmacovigilance (PV) plays a key role in the healthcare system through assessment, monitoring \& discovery of interactions amongst drugs and their effects in human being. Pharmaceutical and biotechnological products are designed to diagnose, prevent or cure diseases. India is the world's second most populated country with over 1 billion potential drug consumers. Although, India is participating in the Uppsala Monitoring Center (UMC) programme, its contribution to that database is relatively small. Signal assessment is mainly performed to analyse the cause and effect by using World Health Organization (WHO) scale \& Naranjo scale of probability. Signal detection and its assessment is very vital and complex process. This article gives a systematic review of the PV in India from its origin to the current scenario and also discusses the various strategies and proposals to build, maintain and implement a robust PV system and to improve the process of ADR reporting in the country.

Keywords: Adverse drug reactions; pharmacovigilance; spontaneous reporting system; Uppsala monitoring centre; causality assessment system;

\section{Introduction}

PV was officially introduced in December 1961 with the publication of a letter in The Lancet by Dr. William McBride, the Australian obstetrician who first suspected a causal link between serious fatal deformities (phocomelia), thalidomide used during pregnancy: Thalidomide was used as an anti-emetic and sedative agent in pregnant women. In 1968, the WHO promoted the 'Programme for International Drug Monitoring' a pilot project aimed to centralize world data on Adverse Drug Reactions (ADRs). In particular, the main aim of the "WHO Programme" was to identify the earliest possible PV signals. The term PV was proposed in the mid-70s by a French group of pharmacologists and toxicologists to define the activities promoting "The assessment of the risks of side effects potentially associated with drug treatment'. WHO defines PV as 'the pharmacological science relating to the detection, assessment, understanding and prevention of ADRs, particularly long-term and short-term ADRs of medicines. PV serves various roles such as identification, quantification and documentation of drug-related problems which are responsible for drug-related injuries. PV is mainly the post marketing surveillance (phase-4 study) of drug development; the main objective of PV is to quantify previously recognized ADRs, to identify unrecognized ADRs, to evaluate the effectiveness of medicines in real-world situations, and to decrease mortality and morbidity associated with ADRs. The UMC located at Uppsala, Sweden co-ordinates the International Drug Monitoring program (IDM). Till now there are 104 official member countries and 33 associate members throughout the world, including developed, developing and under-developed countries. India is the world's second most populated country with over one billion potential drug consumers. Although, India is participating in the UMC program, its contribution to this database is relatively small. This problem is essentially due to the absence of robust ADRs monitoring system and also the lack of awareness of reporting concepts among Indian health care professionals. It is very important to focus the attention of the medical community on the importance of ADRs to ensure maximum benefits for public health and safety. In India ADRs are considered among the leading cause of morbidity and mortality. Approximately $8 \%$ of hospital admissions are estimated due to ADRs and regarding 8-19\% of hospitalized patients experience a serious ADR. When the FDA approves a new drug or marketing, its complete adverse events profile may not be known because of the limitation of pre-approval clinical trials. Typically, clinical trials for new drugs are not of short durations and are conducted in populations that number up to 5000, therefore, the most common dose related ADRs are usually detected in the premarketing phase while ADRs which are rare and those detected on long term use are not Figure.No.1 [1-8].

\section{Types of ADR}

ADR is a response to a drug which is noxious and unintended, and which occurs at doses normally used in human being for the prophylaxis, diagnosis or therapy of disease, or for the modification of physiological function Table.No.1 [9].

\section{Historical background of PV}

The safety of drug was not the early concern in the history of drug. The thalidomide tragedy of 1960s opened the eyes of drug regulators as well as other concern healthcare professionals to establish a way to ensure drug safety. The mile stone in the drug safety was the publication of chloroform related death on The Lancet journal for the first time in 1893. Safety of drug became the global concern and different initiatives were taken by 


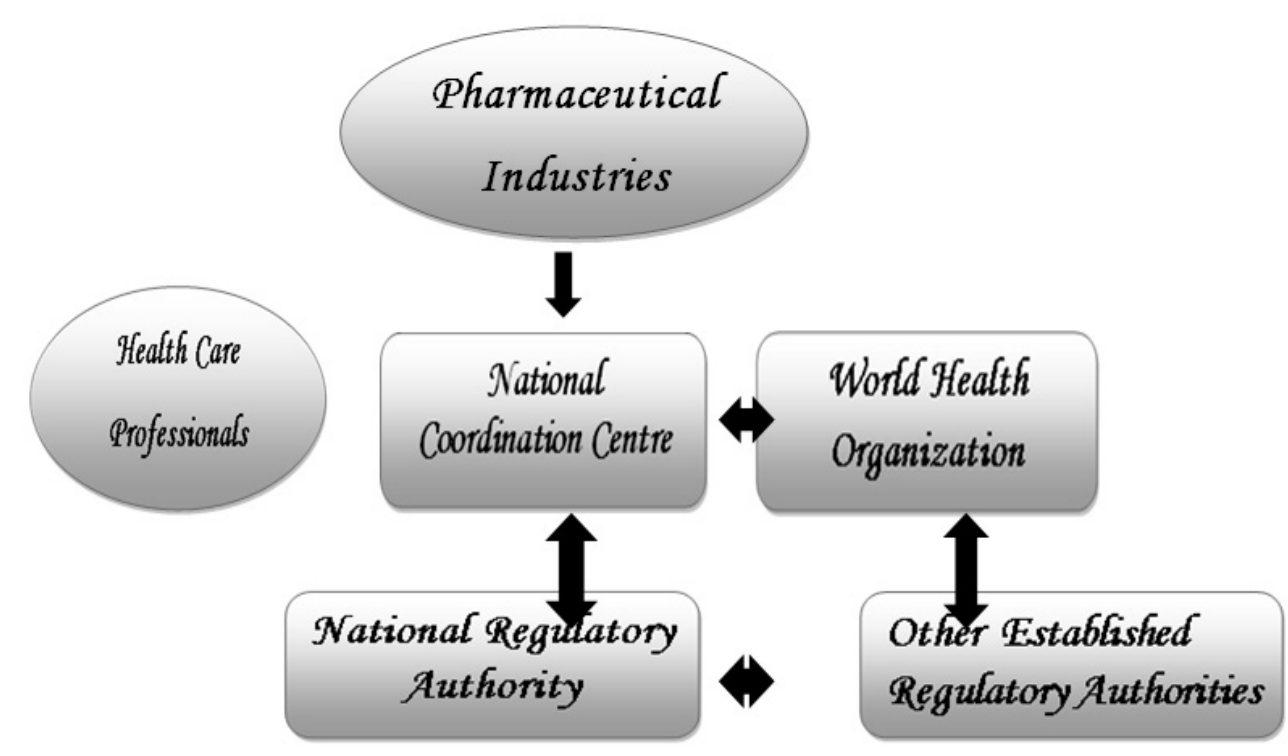

Figure 1: Diagrammatic representation of PV

\begin{tabular}{|c|l|l|l|}
\hline \multicolumn{3}{|c|}{ TYPES OF ADRs } \\
\hline Type & $\begin{array}{l}\text { Type of } \\
\text { effect }\end{array}$ & characteristics & example \\
\hline A & Augmented & $\begin{array}{l}\text { Dose dependent } \\
\text { predicted from the } \\
\text { known } \\
\text { pharmacology of the } \\
\text { drug }\end{array}$ & $\begin{array}{l}\text { Hypoglycaemia- } \\
\text { insulin }\end{array}$ \\
B & Bizarre & $\begin{array}{l}\text { Unpredictable } \\
\text { Dose independent } \\
\text { Rare,fatal } \\
\text { Prolong treatment } \\
\text { After years of } \\
\text { treatment }\end{array}$ & $\begin{array}{l}\text { Anaphylaxis to } \\
\text { penicillin }\end{array}$ \\
\hline C & Chronicicic neuropathy \\
D & Delayed & $\begin{array}{l}\text { Antipsycotic-turdive } \\
\text { dyskinesia }\end{array}$ \\
\hline
\end{tabular}

Table 1:

different countries to safeguard the public health safety. The US FDA act was passed in 1906 for the first time, but it was amended to control misbranding of ingredients and false advertising claims after 107 deaths by the use of di-ethylene glycol as a solvent for sulphanilamide elixir. There were radical changes in the drug safety issues after the worldwide thalidomide tragedy which was first reported by an Australian obstetrician, Dr. William McBride in December 1961.

He reported thalidomide associated serious fatal deformities (phocomelia) used in pregnancy. This drug had not been adequately screened for teratogenicity, but similar malformations were subsequently shown in the rabbit and at high dose in the rat. In West Germany 4000 individuals were affected. The tragedy made the world to be more concern about the drug safety, as efficacy was only the parameter to see the effect of drugs. Immediately after the tragedy the US FDA act was amended to compulsory pre-marketing submission of both efficacy and safety data in 1962. The UK Medicines act was enforced in
1968, however, safety monitoring via 'yellow card system' was introduced in 1964. The drug safety issues were globalised, strengthened and systematized after the establishment of WHO Programme for IDM in 1968 [10,11].

\section{Purpose of PV}

$\mathrm{PV}$ is the science and activities related to the detection, assessment, understanding and prevention of ADRs or any other possible drug-related problems. Recently, its concerns have been widened to include:
1. Herbals Traditional and complementary medicines
2. Blood products
3. Biological products
4. Medical devices
5. Vaccines

\section{Many other issues are also of relevance to the science}

1. Sub-standard medicines

2. Medication errors

3. Lack of efficacy reports

4. Use of medicines for indications that are not approved and for which there is inadequate scientific basis

5. Case reports of acute and chronic poisoning

6. Assessment of drug-related mortality

7. Abuse and misuse of medicines

8. Adverse interactions of medicines with chemicals, other medicines, and food 


\section{The specific aims of PV are to}

1. Improve patient care and safety in relation to the use of medicines and all medical and paramedical interventions

2. Improve public health and safety in relation to the use of medicines

3. Contribute to the assessment of benefit, harm, effectiveness and risk of medicines encouraging their safe, rational and more effective (including cost-effective) use, and

4. Promote understanding, education and clinical training in PV and its effective communication to the public.

PV has developed and will continue to develop in response to the special needs and according to the particular strengths of members of the WHO Programme and beyond. Such active influence needs to be encouraged and fostered; it is a source of vigour and originality that has contributed too much to international practice and standards [12].

\section{Vigi-Flow (India)}

Vigi-Flow is a web-based Individual Case Safety Report (ICSR) management system that is specially designed for use by national centres in the WHO Programme for IDM. It can also be used by pharmaceutical companies or clinical research organisations for monitoring of their ICSR. Vigi-Flow is based on and compliant with the ICH E2B standard and is a trademark of the UMC and maintained by the UMC in Uppsala, Sweden. VIGIBASE is the name of the WHO global ICSR database measure (IC value) stratified in different ways and is useful for filter capabilities. It has been in use for more than 30 years, it is located in Uppsala since 1978 and designed for spontaneous reports, maintained by the UMC.

\section{Yellow Card Scheme}

Yellow card schemes (YCS) were applied to spontaneous reporting systems. The system has become one of the major international PV resources. The yellow cards are classified into seven priorities by a member of the scientific staff according to the drugs and the nature of the ADRs. The YCS is run jointly by the Medicines Control Agency which is the regulatory agency and the Committee on Safety of Medicines which is the experts committee. Since 1991, the YCS has been enhanced by a new computer system, the ADROIT (Adverse Drug Reaction Online Information Tracking) system. ADROIT is different from other databases. Not only does it store the details of the report, but also the image of the yellow card in the optical system. Multiple users can view any yellow card on screen at the same time. The reports are made on priority so that serious ADRs receive early attention Fig.No.2.

\section{Naranjo's Probability Scale}

Naranjo's probability scale is the most commonly used causality assessment method, which has gained popularity among clinicians because of its simplicity. It is a structured, transparent, consistent and easy to apply assessment method. The Naranjo's criteria classifies the probability that an ADR is related to the drug therapy based on a list of questions, which examine factors such as the temporal association of drug administration and event occurrence, alternative causes for the event, drug levels, doseresponse relationships and previous patient experience with the medication. The ADRs are assigned to a probability category from the total score as follows:

- definite if the overall score is 9 or greater,

- probable for a score of 5-8,

- possible for 1-4 and

- doubtful if the score is 0

The Naranjo's criteria do not take into account drug-drug interactions. Drugs are evaluated individually for causality, and points are deducted if another factor may have resulted in the ADRs, thereby weakening the causal association. The Naranjo Scale was originally developed to assess the drug and its ADRs analysis at therapeutic dose. It has not been validated for use in patients that are critically ill, suffer specific organ toxicity or overdose. Application of the Naranjo's Scale in the overdose setting is not scientifically valid [13-15].

\section{The WHO-UMC causality assessment system}

The WHO-UMC system has been developed in consultation with the National Centres participating in the Programme for IDM and is meant as a practical tool for the assessment of case reports. It is basically a combined assessment taking into account the clinical-pharmacological aspects of the case history and the quality of the documentation of the observation. Since PV is particularly concerned with the detection of unknown and unexpected ADRs, other criteria such as previous knowledge and statistical chance play a less prominent role in the system. It is recognised that the semantics of the definitions are critical and that individual judgements may therefore differ. There are other algorithms that are either very complex or too specific for general use. This method gives guidance to the general arguments which should be used to select one category over another. The various causality categories are listed in Table.No.2. The assessment criteria of the various categories are shown in a point-wise way, as has been developed for practical training during the UMC Training courses [16].

\section{WHO-UMC \& India}

The WHO Program for IDM provides a forum for WHO member states that include India to collaborate in the monitoring of drug safety. Within the program, individual case reports of suspected ADRs are collected and stored in a common database, presently containing over 3.7 million case reports. Since 1978, the UMC in Sweden has carried out the Program. The UMC is responsible for the collection of data ADRs from around the world, especially from countries that are members of the WHO including India. Member countries send their reports to the UMC where they are processed, evaluated and entered into the WHO International Database. When there are several reports of ADRs to a particular drug this process may lead to the detection of a signal-an alert about a possible hazard communicated to member countries. This happens only after detailed evaluation \& expert review. 
SUSPECTED ADVERSE DRUG REACTION REPORTING FORM

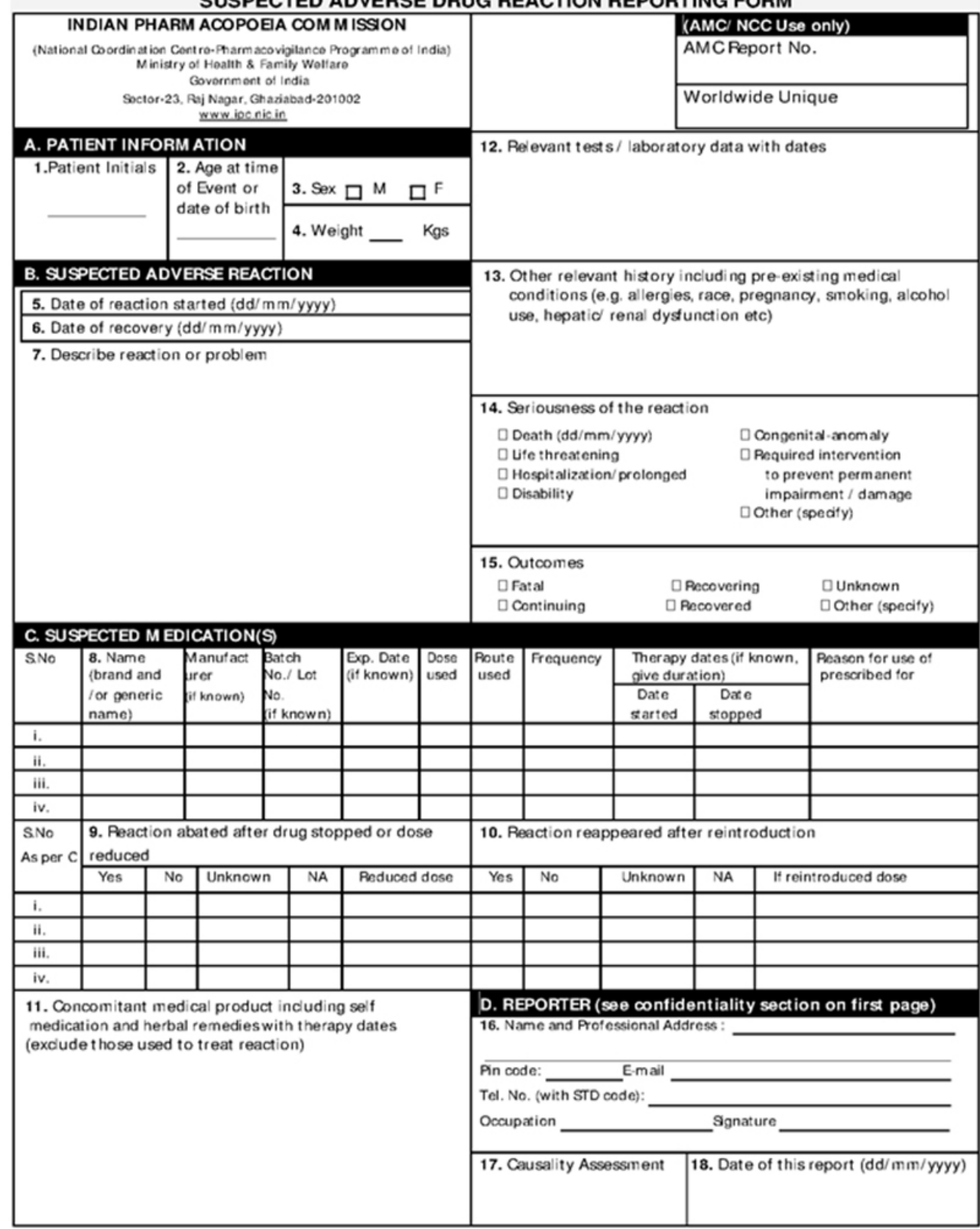

Figure 2: Suspected Adverse Drug Reaction Reporting Form

Table No.2: Causality assessment criteria

\begin{tabular}{|l|l|}
\hline Causality term & Assessment criteria \\
\hline Certain & $\begin{array}{l}\text { • Event or laboratory test abnormality, with plausible time relationship to drug intake } \\
\text { - Cannot be explained by disease or other drugs } \\
\text { • Response to withdrawal plausible (pharmacologically, pathologically) } \\
\text { • Event definitive pharmacologically or phenomenologically } \\
\text { (i.e. an objective and specific medical disorder or a recognised } \\
\text { pharmacological phenomenon) } \\
\text { • Rechallenge satisfactory, if necessary }\end{array}$ \\
\hline
\end{tabular}




\begin{tabular}{|l|l|}
\hline Probable/Likely & $\begin{array}{l}\text { - Event or laboratory test abnormality, with reasonable time relationship to drug intake } \\
\text { - Unlikely to be attributed to disease or other drugs } \\
\text { - Response to withdrawal clinically reasonable } \\
\text { - Rechallenge not required }\end{array}$ \\
\hline Possible & $\begin{array}{l}\text { - Event or laboratory test abnormality, with reasonable time } \\
\text { relationship to drug intake } \\
\text { - Could also be explained by disease or other drugs } \\
\text { - Information on drug withdrawal may be lacking or unclear }\end{array}$ \\
\hline Unlikely & $\begin{array}{l}\text { - Event or laboratory test abnormality, with a time to drug intake } \\
\text { that makes a relationship improbable (but not impossible) } \\
\text { - Disease or other drugs provide plausible explanations }\end{array}$ \\
\hline Conditional/Unclassified & $\begin{array}{l}\text { - Event or laboratory test abnormality } \\
\text { - More data for proper assessment needed } \\
\text { - Additional data under examination }\end{array}$ \\
\hline Unassessable/Unclassifiable & $\begin{array}{l}\text { - Report suggesting an adverse reaction } \\
\text { - Cannot be judged because information is insufficient or contradictory } \\
\text { - Data cannot be supplemented or verified }\end{array}$ \\
\hline
\end{tabular}

These ADRs reports are assessed locally and may lead to action within the country. Through membership of The WHO IDMP, a country can know if similar reports are being made elsewhere. (The European Union also has its own scheme.) India is a country with a large patient's pool and healthcare professionals, yet ADRs reporting is in its infancy [17-19].

\section{Pharmacovigilance Programme of India (PvPI)}

A National PV Centre is located in the Department of Pharmacology, All India Institute of Medical Sciences (AIIMS), New Delhi and two WHO special centres are located in Mumbai (KEM Hospital) and Aligarh (JLN Hospital). These centres were to report ADRs to the drug regulatory authority of India. The major role of these centres was to monitor ADRs to medicines marketed in India. The Central Drugs Standard Control Organization (CDSCO), Directorate General of Health Services under the aegis of Ministry of Health \& Family Welfare, Government of India in collaboration with Indian Pharmacopeia Commission (IPC), Ghaziabad, (U.P.) is initiating a nation-wide PV programme for protecting the health of the patients by assuring drug safety. The programme shall be coordinated by the IPC as a National Coordinating Centre (NCC). The centre will operate under the supervision of a Steering Committee. The PvPI was initiated by the Government of India on 14 July 2010 with the AIIMS, New Delhi as the NCC for monitoring ADRs in the country for safeguarding Public Health. In the year 2010, 22 ADRs monitoring centres including the All India Institute of Medical Sciences (AIIMS) New Delhi, were set up under this programme. To ensure implementation of this programme in a more effective way, the NCC was shifted from the AIIMS, to the IPC on 15 April 2011.

\section{International Collaboration}

The following organizations play a key collaborative role in the global oversight of PV.

\section{The World Health Organization}

The principle of international collaboration in the field of $\mathrm{PV}$ is the basis for the WHO Programme for IDM, through which over 150 member nations have systems in place that encourage healthcare personnel to record ADRs of drugs in their patients. These reports are assessed locally and may lead to action within the country. Since 1978, the programme has been managed by the UMC to which member countries send their reports to be processed, evaluated and entered into an international database called Vigi-Base. Membership in the WHO Programme enables a country to know if similar reports are being made elsewhere. When there are several reports of ADRs to a particular drug, this process may lead to the detection of a signal, and an alert about a possible hazard communicated to member countries after detailed evaluation and expert review $[20,21]$.

\section{The International Council for Harmonisation (ICH)}

ICH is a global organization with members from the European Union, the United States and Japan; its goal is to recommend global standards for drug companies and drug regulatory authorities around the world, with the ICH Steering Committee (SC) overseeing harmonization activities. Established in 1990, each of its 6 co-sponsors-the European Federation of Pharmaceutical Industries and Associations, Japan's Ministry of Health, Labour and Welfare, the Japanese Pharmaceutical Manufacturers Association, the FDA, and the Pharmaceutical Research and Manufacturers of America-have 2 seats on the SC. Other parties have a significant interest in ICH and have been invited to nominate observers to the SC; 3 current observers are the WHO, Health Canada, and the European Free Trade Association, with the International Federation of Pharmaceutical Manufacturers Association participating as a non-voting member of the SC [22].

\section{The Council for International Organizations of Medical Science (CIOMS)}

CIOMS a part of the WHO is a globally oriented think tank that provides guidance on drug safety related topics through its Working Groups. The CIOMS prepares reports that are used as a reference for developing future drug regulatory policy and procedures, and over the years, many of CIOMS proposed policies have been adopted. Examples of topics these reports have covered include: Current Challenges in PV: Pragmatic Approaches (CIOMS V); Management of Safety Information from Clinical Trials (CIOMS 
VI); the Development Safety Update Report: Harmonizing the Format and Content for Periodic Safety Reporting During Clinical Trials (CIOMS VII); and Practical Aspects of Signal Detection in PV: Report of CIOMS Working Group (CIOMS VIII).

\section{The International Society of PV (ISoP)}

ISoP is an international non-profit scientific organization, which aims to foster PV both scientifically, educationally and enhance all aspects of the safe and proper use of medicines, in all countries. It was established in 1992 as the European Society of PV.

\section{Future perspectives}

For, the problems \& challenges facing the development of a robust PV system of India, the following proposals might be as follows:

1. Build \& maintain a vigorous PV system.

2. Making PV reporting mandatory and introducing PV inspections.

3. High-level discussions with various stakeholders.

4. Creating a single country-specific ADRs reporting form to be used by all.

5. Strengthen the Drug Controller General of India (DCGI) office with trained scientific and medical assessors for PV.

6. Creating a clinical trial and post-marketing database for SAEs / SUSARs and ADRs for signal detection and access to all relevant data from various stakeholders.

7. Education and training of medical students, pharmacists and nurses in the area of PV.

8. List all new drugs/indications by maintaining a standard database for every pharmaceutical company.

9. Collaborating with PV organizations in enhancing drug safety with advancements in information technology, there has been the emergence of new opportunities for national and international collaborations that can enhance post-marketing surveillance programs and increase drug safety.

10. Building a network of PV and pharmacopeidemiologists in India.

\section{Conclusion}

The PV in India continues to grow, evolve, and improve. India is the largest producer of pharmaceuticals and now emerging as an important clinical trial hub in the world. The DCGI has shown its commitment to ensure safe use of drugs by establishing the National PV Program. PV may not rely upon one single method, but needs a strategy of complementary activities. The quality of the reports can be increased through proper training and retraining of the personnel engaged in the PV activity. A suitably working PV system is important if medicines are to be used prudently. It will be advantageous for healthcare professionals, regulatory authorities, pharmaceutical companies and consumers to monitor medicines for risk. Thus, a world class PV system can definitely be empowered in India.

\section{References}

1. WHO. The Importance of Pharmacovigilance: Safety Monitoring of medicinal products. 2002;

2. Singh KNM and Kanase HR. Pharmacovigilance Programme of India: The Beginning, Current Status and Recent Progress. Adv Pharmacoepidemiol Drug Saf. 2017;6(4):1-4. Doi: 10.4172/21671052.1000219

3. Pharmacovigilance. World Health Organization. 2017;

4. Kalaiselvan V, Thota P, Singh GN. Pharmacovigilance Programme of India: Recent developments and future perspectives. Indian J Pharmacol. 2016;48(6):624-628. Doi: 10.4103/0253-7613.194855

5. PvPI Reaches out to rural masses. Newsletter Pharmacovigilance Programme of India. 2017;

6. Pharmacovigilance \& Risk Management Strategies Forum. 5th Annual Flemming Conference, Philadelphia, PA. 2018;

7. Kenneth FS and David AG. Case-control studies: research in reverse. Lancet. 2002;359(9304):431-434. Doi: 10.1016/S01406736(02)07605-5

8. Honig PK. Advancing the science of pharmacovigilance. Clin Pharmacol Ther. 2013;93(6):474-475. Doi: 10.1038/clpt.2013.60

9. Williams D and Feely J. Underreporting of adverse drug reactions: attitudes of Irish doctors. Ir J Med Sci. 1999;168(4):257-261.

10. McBride WG. Thalidomide and congenital abnormalities. Lancet. 1961;278(7216):1358.

11. Olsson S. The role of the WHO Programme for International Drug Monitoring in coordinating worldwide drug safety efforts. Drug Saf. 1998;19(1):1-10.

12. Edwards IR. The accelerating need for pharmacovigilance. J R Colle Physicians Lond. 2000;34(1):48-51.

13. Moore N. The role of the clinical pharmacologist in the management of ADRs. Drug Safety. 2001;24(1):1-7.

14. Kulkarni RD. Reporting system for rare side effects of non-narcotic analgesics in India: Problems and opportunities. Medical Toxicology. 1986;1:110-113.

15. Gandhi TK, Weingart SN, Borus J, Seger AC, Josh Peterson, Elisabeth Burdick, et al. Adverse drug events in ambulatory care. N Engl J Med. 2003;348:1556-1564. Doi: 10.1056/NEJMsa020703

16. World Health Organization (WHO). Uppsala Monitoring Centre: The use of the WHO-UMC system for standardized case causality assessment. 2005;

17. Chyka PA and McCommon SW. Reporting of ADRs by poison control centres in the US. Drug Saf. 2000;23(1):87-93.

18. Dal Pan GJ. Ongoing challenges in pharmacovigilance. Drug Saf. 2014;37(1):1-8. Doi: 10.1007/s40264-013-0123-x

19. Lazarou J, Pomeranz BH, Corey PN. Incidence of adverse drug reactions in hospitalized patients: A meta-analysis of prospective studies. JAMA. 1998;279915):1200-1205.

20. Folb PI and Olliaro P. Pharmaceutical policies and regulatory control. WHO Drug Information. 2000;14(2):82-84.

21. Evans SJ. Pharmacovigilance: a science or fielding emergencies?. Stat Med. 2000;19(23):3199-3209.

22. Wieniawski W. International harmonization of regulatory activities: future options. WHO Drug Information. 2000;14(3):145-159. 